\title{
A concepção sistêmica triádica do cérebro e o processo de ensino-aprendizagem da leitura e escrita
}

\author{
The triadic systematic conception of the \\ brain and the teaching-learning process \\ of reading and writing
}

\author{
Rosemeri Terezinha Hoffmann NOGUEIRA* \\ Maria Virgínia Bernardi BERGER**
}

Resumo: Este artigo trata de uma pesquisa-ação realizada na área da Língua Portuguesa, durante o ano de 2003. Teve por objetivo o letramento de uma turma de alunos de 5 a. série do Ensino Fundamental, caracterizada por elevado índice de repetência e dificuldades de aprendizagem. As questões que orientaram o estudo foram: como conduzir o processo de ensino da leitura e escrita junto a alunos com histórico de fracasso escolar e estigmatizados socialmente? Como integrar no trabalho educativo os avanços da ciência do cérebro? Como adequar o processo de ensino-aprendizagem à estrutura e dinâmica de funcionamento do cérebro triúnico? Quais as estratégias didático-metodológicas mais adequadas para despertar o interesse, a participação e o aprendizado na sala de aula? Utilizou-se de uma metodologia de ensino fundamentada na concepção sistêmica triádica do cérebro e estratégias de intervenção adequadas às peculiaridades cognitivas, afetivas e comportamentais dos alunos. Os indicadores da pesquisa foram obtidos por meio de fichas individuais e produção escrita dos alunos, os quais analisados revelaram que houve mudança qualitativa na auto-imagem e avanços significativos na aprendizagem da leitura e escrita desse grupo de alunos. Tais resultados mostram o impacto positivo da metodologia sistêmica triádica e das estratégias alternativas de letramento para o trabalho educativo de alunos com histórico de fracasso escolar.

Palavras-chave: criatividade, ensino-aprendizagem, metodologia sistêmica triádica

\footnotetext{
* Especialista em Literatura da Língua Portuguesa pela UEPG. Email: prof_rosemeri@yahoo.com.br

${ }^{* *}$ Mestre em Educação (Psicologia da Educação pela PUC-SP. Doutora em Educação pela UNICAMP. Professora do Departamento de Educação e do Programa de Mestrado em Educação da Universidade Estadual de Ponta Grossa - UEPG. Email: mvbberger@uol.com.br
}

Olhar de professor, Ponta Grossa, 8(1): 171-186, 2005. 


\begin{abstract}
This article deals with a research-action done in the area of Portuguese language in 2003. Its aim was the literacy of 5th grade students in Elementary School with learning difficulties and many of which failing their exams thus repeating the school year. The questions that oriented the study were: in what way could reading and writing be taught to students with a history of school failure and socially marginalized? How could one integrate advances in science related to the brain and educational work? How could the process of teaching-learning be adjusted to the structure and dynamics of functioning of the triadic brain? What are the most adequate didactic-methodological strategies to raise interest, paricipation and learning in the classroom? The teaching methodology used was based on the triadic systematic conception of the brain plus intervention strategies appropriate for the cognitive, affective and behavioural patterns of the students. The research indicators were obtained from individual files and students' written production. Once analyzed, these revealed a qualitative change in the self-image and significant advances in learning reading and writing in this group of students. These results show the positive impact of the triadic systematic methodology and the alternative strategies for literacy in an educational work on students with a history of school failure.
\end{abstract}

Key words: creativity, teaching-learning, triadic systematic methodology

\author{
A vida precisa ser reconhecida (cérebro básico) \\ Anseia por ser amada (cérebro límbico) $e$ \\ Busca expressar-se (neocórtex) \\ A vida é!
}

Beauport e Diaz (1998)

\section{PROBLEMATIZAÇÃO}

Há dez anos leciono Língua Portuguesa em escolas públicas e, durante esse tempo, sempre trabalhei com turmas de quintas séries de Ensino Fundamental. Mas, a cada ano que passa, percebo que as crianças estão ingressando nessa série com dificuldades de aprendizagem na leitura e na escrita, pouca capacidade de concentração e interesse pelo aprendizado. O comportamento dos alunos manifesta inquietação, irritabilidade, ansiedade e indisciplina. Estudos realizados por Goldestein e Goldestein (1998); Oliveira (1999, 2001); Zagury (1999); Ronchim (1999) vêm confirmando minhas observações e procuram explicar essas dificuldades que estão subjacentes ao não-aprender. 
Através de um processo de reflexão sistemática ao longo desses anos, levantei algumas hipóteses sobre as variáveis causais dessa problemática: o excesso de estímulos visual e sonoro produzidos pela mídia (TV, Internet, Lan House), que atingem o território da emoção com mais eficiência que o professor; a quantidade de informações a serem processadas pela memória; os hábitos de consumo, que geram necessidades e desejos insaciáveis de bens materiais e, por conseqüência, frustrações, insegurança, medo. Os alunos remetem ao espaço escolar modelos sociais, não só os mostrados pela televisão, como também aqueles modelos indisciplinados do cotidiano que se tornam figuras de evidência, o que promove a aprendizagem social do comportamento indisciplinado, já que a disciplina não é tarefa só dos pais e da escola, pois envolve todo o campo relacional do indivíduo. A disciplina, afirma Román (1997), “é uma construção coletiva, é algo que não podemos isolar do contexto em que vivemos".

A escola como sistema microssocial espelha o macrossocial e, no âmbito do trabalho educativo da leitura e escrita, não tem conseguido acompanhar e fazer frente às novas tecnologias de informação que caracterizam a sociedade do conhecimento. As metodologias de ensino continuam presas a modelos tradicionais que privilegiam a repetição e a memorização, sem levar em conta os sabe- res e experiências dos alunos. Supõese que os professores tenham tido em sua formação inicial subsídios teóricos metodológicos sobre as abordagens sócio-construtivistas; contudo, parece que há um fosso entre o que os professores aprendem na teoria e a sua aplicação na prática pedagógica. O processo de ensino-aprendizagem do vernáculo tem se configurado na maioria das vezes apenas como um conjunto de normas a serem memorizadas e o livro didático continua sendo para muitos professores o único material de apoio. O mais grave, porém, consiste no desprezo à atividade de representação simbólica e interativa dos alunos no aprendizado da leitura.

Como conduzir o processo de ensino da leitura junto a alunos com histórico de fracasso escolar e estigmatizados socialmente? Quais as estratégias didático-metodológicas mais adequadas para despertar 0 interesse, a participação e o aprendizado na sala de aula? Foi a busca de respostas para essas questões, assim como o compromisso de democratização e inclusão social, que me impulsionaram no exercício do trabalho docente, que impulsionaram a mudança nos fundamentos e nos procedimentos didático-metodológicos adotados junto a esse grupo de alunos e que continuam me inspirando no exercício do trabalho docente. 


\section{FUNDAMENTOS TEÓRICOS}

Os estudos realizados por Peirce ${ }^{1}$ no campo da semiótica enfatizam a importância de olhar para o mundo e procurar compreendê-lo a partir da linguagem dos signos, de seus objetos e interpretantes. Nesse processo, o autor destaca o papel da fenomenologia, a qual lhe permitiu chegar à definição das três categorias lógicas que podem ser aplicadas no campo das manifestações psicológicas, exemplificando como se dá a apreensão dos fenômenos na consciência.

Qualidades de sentimento constituem a primeira categoria, denominada primeiridade; não são nem pensamentos articulados, nem sensações, mas partes constituintes da sensação e do pensamento. Qualidade de sentiré o modo mais imediato, medializado de nosso estar no mundo. Sentimento é, pois, um quase signo do mundo.

A arena das coisas cotidianas, o mundo real, independente do pensamento e, no entanto, pensável, é o que caracteriza a segunda categoria. Estamos continuamente esbarrando em fatos que nos são externos, tropeçando em obstáculos, coisas reais que não cedem ao mero sabor das nossas fantasias. A factualidade do existir secundidade - está na corporificação material. A qualidade de sentimento é puro sentir, antes de ser percebido como existindo num eu. Por isso qualquer sensação já é secundidade: ação de um sentimento sobre nós e nossa reação específica. O mundo é aquilo que a experiência nele inculca. E experiência em nós é aquilo que o fluxo da vida nos impeliu a pensar. É por isso que a experiência, o não-ego, o outro constituem-se no verdadeiro pivô do pensamento, aquilo que move o pensar. Falar em pensamento, segundo Santaella (1990), é falar em processo, mediação interpretativa entre nós e os fenômenos.

A terceridade corresponde à inteligibilidade, ou pensamentos em signos, através da qual representamos o mundo - a síntese intelectual, elaboração cognitiva. Diante de qualquer fenômeno, isto é, para conhecer e compreender qualquer coisa, a consciência produz um signo, ou seja, um pensamento como mediação entre nós e os fenômenos. O simples ato de olhar já está carregado de interpretação, visto que é sempre o resultado de uma elaboração cognitiva, fruto de uma mediação sígnica que possibilita a orientação no espaço por um reconhecimento diante das coisas que só o signo permite. Compreender, interpretar é traduzir um pensamento, em outro pensamento, num movimento ininterrupto. Esses três possíveis

${ }^{1}$ Charles Sanders Peirce (1839-1914), cientista-lógico-filósofo cujos estudos deram origem à Semiótica, ciência que tem por objeto de investigação todas as linguagens possíveis. (SANTAELLA, 1990, p. 15).

$\overline{174}$ Olhar de professor, Ponta Grossa, 8(1): 171-186, 2005. 
estados da mente, afirma Peirce, não podem ser entendidos como estanques:

Nenhuma linha firme de demarcação pode ser desenhada entre diferentes estados integrais da mente, isto é, entre estados tais como sentimento, vontade, conhecimento. É claro que estamos ativamente conhecendo em todos os minutos de vigília e realmente sentindo também. Se não estamos sempre querendo, estamos pelo menos, a todo momento, com a consciência reagindo em relação ao mundo externo. (PEIRCE apud SANTAELLA, 1990, p. 71).

Como teoria científica, a Semiótica de Peirce criou conceitos e dispositivos de indagação que nos permitem descrever, analisar e interpretar linguagens. Como tal, os conceitos são instrumentos para o pensamento, lentes para o olhar, amplificadores para a escuta. Não podem, por si mesmos, substituir a atividade da leitura e desvendamento da realidade, mas são instrumentos que, seriamente decifrados e empregados, auxiliam nessa atividade.

A visão de consciência proposta por Peirce é ampla e se aproxima das modernas pesquisas sobre o cérebro humano realizadas por Karl Pribam (as recordações e informações podem estar organizadas e associadas em forma de holograma e não localizadas como uma estante); Roger Sperry (cérebro diádico, demonstra as diferenças entre os dois hemisférios corticais no que se refere às especializações e às funções); Paul MacLean (o cérebro humano é triúnico, composto de três subcérebros separados e relativamente independentes, os quais são reflexo de nossa herança evolutiva).

O neuropsicólogo A. R. Luria concebe o cérebro como um sistema dinâmico desdobrado em três blocos funcionais e postula a abordagem de estudo do cérebro sob o princípio de integração. Essas pesquisas revelam, segundo Mahoney (1998), as complexas relações entre os processos afetivos, cognitivos e físicos implicados na aprendizagem humana. Infelizmente, no campo educativo esses estudos ainda não produziram o impacto que era de se esperar, principalmente quanto às metodologias e práticas de ensino.

Como integrar esses conhecimentos no trabalho educativo? De que modo adequar o processo de ensinoaprendizagem à estrutura e dinâmica de funcionamento do cérebro triúnico? Como se dá a apreensão dos fenômenos pela consciência no processo de ensino-aprendizagem da leitura e escrita?

Muitas vezes, o insucesso do estudante é entendido como o fracasso da escola em lidar com a diversidade. O lapso está em não se perceber que em uma sala há 30 ou 40 singularidades das quais o professor espera resposta única. Se há muitas maneiras de aprender, devem existir múltiplas formas de ensinar. Infelizmente, não é levada em conta, no processo de en- 
sino-aprendizagem, a comunicação em rede entre os três cérebros: Neocórtex (Lógica, cognição, associação, comparação de idéias, imagens, intuição); Límbico (Sensibilidade, emoções, sentimentos, motivação) e Básico/ Reptiliano (Comportamentos, rotinas, hábitos, rituais, senso de organização e praticidade).

A concepção sistêmica triádica considera os três processos mentais integrados num único ciclo e tem características de um holograma: "cada parte contém o todo e o todo é mais que a soma aritmética das partes, já que cada função pode se tomada como eixo das demais, sucessivamente (MAIA, 2002, p. 158). O Método Sistêmico Triádico avança em relação aos métodos de ensino diretivo e não diretivo, porque é participativo: professor e aluno interagem, trocam e aprofundam conhecimentos. E, ao planejar o trabalho pedagógico, o professor leva em consideração as funções dos três cérebros:

\begin{tabular}{lll}
\hline Cérebro Neocórtex & Cérebro básico/reptíliano & Cérebro Límbico \\
\hline Domínio de conteúdo & Organização do ambiente & Entusiasmo \\
Articulação de idéias & Uso de técnicas pedagógicas & Relações Interpessoais \\
Comunicação verbal & Administração do tempo & Comunicação não verbal \\
Correção gramatical & Administração do grupo & Propósito do estudo \\
Adequação do conteúdo & Levar o conteúdo à prática & Integração da turma à clientela \\
\hline
\end{tabular}

Os estudos sobre o cérebro triádico foram aplicados na área da educação por Beauport e Diaz (1998); Araújo (2002); Maia (2002); Colandi (1998, 2003), para auxiliar o educador a compreender a dinâmica do ensinar e do aprender.

A criança quando nasce, traz potencialidades latentes para os três blocos de funções mentais.... Assim no lado esquerdo todos trazem a potencialidade para a linguagem; para a porção central todos trazem o instinto reptílico, que lhes possibilita ações de sobrevivência e para o lado direito potencial para a sensibilidade, amor, etc. (COLANDI, 1998, p.93)

Segundo Colandi (1998), os três processos são simultâneos e continuam a desenvolver-se ou a reajustar-se em todas as idades, tanto autônoma como integradamente, reque- 
rendo estímulo, cultivo e avaliação.

Se a criança traz potencialidades latentes, cabe à escola proporcionar uma educação pela e para globalidade, buscando propostas que possam contemplar de forma mais dinâmica e flexível o pressuposto de uma concepção sistêmica globalista, aberta, proporcional. Vivenciada na prática, tal concepção liberta as mentes do teor fragmentado, mecânico e reducionista, ou seja, dos modelos escolares que privilegiam as funções racionais e associativas da mente.

$\mathrm{Na}$ Área de Língua Portuguesa, o trabalho pedagógico de letramento poderia avançar se fossem melhor compreendidas as dinâmicas organiza-cionais do cérebro triádico, principalmente a sua natureza aberta a reorganizações. Professores que atuam junto a alunos com histórico de fracasso escolar são capazes de relatar episódios de intensa angústia emocional desses alunos, reflexo da expressão natural saudável das lutas do aluno pela reorganização de suas estruturas cognitivas. Tais lutas nem sempre são bem sucedidas, é claro, mas devem ser vistas com menos medo ou impaciência (da parte do professor e da parte do próprio aluno), se forem compreendidas como atividades de um sistema aberto e em desenvolvimento na busca de um "equilíbrio mais extensivo" com seu mundo. As dinâmicas de desenvolvimento parecem ser não lineares e fundamentalmente baseadas no aparente caos da des/ reorganização sistêmica.

\section{DO PROBLEMA PARAATEORIA E AÇÃO PEDAGÓGICA}

As sugestões para desenvolver as funções mentais do hemisfério direito incluem brincadeiras, dramatizações, simbolização, oração, criatividade, música, atividades artísticas, relacionamentos. Ou seja, ao ativar esse hemisfério estaremos estimulando a dimensão intuitiva, sensível, criativa do ser humano. Desconsi-derálo pode incorrer em algumas dificuldades de aprendizagem como: analfabetismo não-verbal, icônico, e falta de gosto pela escola. Ao hemisfério esquerdo correspondem as funções relativas à aquisição de conceitos, à escrita, à leitura, à comunicação, à matemática, à gramática. A escassez de vocabulário, lentidão na leitura, desatenção, dificuldades em estabelecer relações apontam para a necessidade de propor atividades que estimulem esse hemisfério. $O$ cérebro central ou reptiliano é responsável pelas atividades motoras, pelo planejar e executar ações em interação com o meio físico e social. Desconsiderá-lo no trabalho pedagógico pode comprometer o desenvolvimento da consciência corporal, aquisição de hábitos, disciplina e noção de limites. O espírito empreendedor, as metas e a motivação também serão afetados. Ao reconhecer a complexidade da organização cerebral, o professor é estimulado a transcender os limites de uma prática tradicional e experimentar novas iniciativas metodológicas. 


\section{A EXPERIÊNCIA}

Tive uma experiência fascinante no ano de 2003, quando pude refletir e agir sobre a própria prática educativa, em uma das escolas que trabalho, com uma $5^{\text {a }}$. série em especial: alunos com idade de 13 a 14 anos que, por sua vez, eram repetentes e/ ou desistentes de anos anteriores. Era uma turma agitadíssima, que não se concentrava, apresentava comportamentos violentos e déficit de aprendizagem. Resolvi, então, dar início a um projeto de letramento nessa turma, fundamentado na concepção sistêmica triádica do cérebro. Na seqüência, reorganizei totalmente o planejamento da disciplina, para adequála à especificidade dessa turma.

$\mathrm{O}$ trabalho pedagógico era realizado no decorrer de duas aulas semanais, porque a disciplina em questão não fazia parte do núcleo comum e sim da parte diversificada do currículo. O perfil da turma, veiculado entre os membros da escola, era permeado de concepções e preconceitos: "repetentes", já haviam abandonado a escola outras vezes", "não queriam nada com nada". No entanto, sem deixar-me influenciar pelos "estigmas", elaborei um questionário (Anexo 1), tendo por referência os 14 subsistemas sociais de A. Rubbo Muller, obtidos em Colandi (2003), para conseguir coletar indicadores concretos que possibilitassem construir o perfil da turma e planejar o trabalho pedagógico. As perguntas foram adapta- das à faixa etária dos alunos e tinham por objetivo identificar as necessidades e dificuldades de cada um, e as variáveis do meio ambiente que poderiam estar interferindo no processo de ensino- aprendizagem.

As questões foram respondidas pelos alunos com ajuda de seus familiares, os quais foram entrevistados pelos próprios alunos. Dentre as questões, as mais relevantes foram as que se referiam a situação familiar (número de filhos, moradia, estado civil dos pais, relacionamento familiar, emprego ou desemprego). Houve também questões relacionadas à saúde, alimentação e vestuário, visando identificar os vícios e hábitos alimentares. O lazer também mereceu destaque, porque possibilitou tomar conhecimento sobre como os alunos ocupavam o tempo livre. Quanto à educação, o objetivo era identificar a procedência desses alunos, meios de locomoção, o que pensavam sobre a escola e o que esperavam dela. Buscouse identificar a religião ou crenças para compreender a visão de mundo desses alunos. A linguagem em gíria, outros idiomas falados na familia, o acesso à $\mathrm{TV}$, rádio, jornais e telefone também foram sondados.

Após o levantamento, procedi à análise dos dados e constatei que a maioria desses alunos era oriunda de camadas sociais desfavorecidas, procedente de escolas municipais, possuía vícios como tabagismo e álcool, a alimentação era precária, não tinha acesso ao lazer, e, em geral, os pais 
eram desempregados. Alguns moravam em casa de parentes, faziam parte de gangues, recebiam bolsa-escola e freqüentavam a escola por esse motivo. Em relação à linguagem, utilizavam a linguagem própria do grupo social a que pertenciam. Constatei que para esses alunos a escola era considerada "uma prisão". Eles não manifestavam emoção positiva em freqüentá-la. A análise desses indicadores possibilitou-me tomar a decisão de iniciar o trabalho educativo junto a turma estimulando sua a sensibilidade, emoções e sentimentos. Compreendi a importância de criar um vínculo emocional de confiança com esses alunos, já que eles queriam ser reconhecidos e valorizados como pessoas, almejavam ter espaço para expressar seus sentimentos de amizade com os colegas e comigo, bem como desejavam ser valorizados e reconhecidos.

As informações do questionário foram organizadas em fichas individuais e retomadas na medida em que pudessem subsidiar as ações educativas. Na seqüência, realizei uma sondagem sobre a competência de leitura e de escrita de cada aluno, e constatei que eram altamente deficitárias. Os resultados foram anotados nas fichas, bem como o progresso no aprendizado. As fichas tornaram-se instrumento de coleta de dados e acompanhamento individual dos alunos.

Sabe-se que a emoção é que determina a qualidade de um registro mnemônico e o que, quanto maior o volume emocional envolvido numa experiência, mais o registro será privilegiado e mais chances terá de ser resgatado. Com base nesse pressuposto, iniciei a aplicação da metodologia sistêmica triádica. Planejei atividades que propiciassem a interação e a integração dos alunos, utilizando estímulos que ativassem o hemisfério direito do cérebro, com atividades criativas em que pudessem explorar o lado artístico, como a pintura, modelagem, música e jogos. Privilegiei as dinâmicas de grupo e os trabalhos em equipes (definidas por cores e por sorteio). Fiz uso de mímicas e jogos de adivinhações. Organizamos uma escala entre os alunos, para que cada um tivesse a oportunidade de trazer um texto relacionado à sua religião ou uma oração para a abertura da aula. Técnicas de sensibilização e de relaxamento foram utilizadas com o objetivo de unir a turma, obter a atenção e concentração nas aulas e desenvolver a consciência corporal. Em poucas semanas, foi possível observar que aumentava entre os alunos a motivação, a participação e o interesse pelo aprendizado.

Nas semanas que se seguiram, comecei a introduzir a leitura por meio de vários tipos de imagens e fui ensinando os alunos a "ver" por intermédio da exploração dos sentidos, os quais eram utilizados como antenas de captação de mensagens verbais e não-verbais, visíveis e invisíveis dos textos. Telas de pintores (Picasso, Van Gogh) foram utilizadas na leitura e 
releitura dessas obras. Foi realizada análise de propagandas da TV, revistas e jornais. A partir daí, transformamos imagens em texto escrito e texto escrito em imagens. Dessa maneira, integrávamos o hemisfério direito e esquerdo com atividades relativas ao cérebro básico, como pintar, desenhar, dramatizar, dançar. No decorrer do processo, os alunos foram apresentando mudanças significativas na forma de interagirem uns com os outros e nas atitudes frente ao aprendizado da leitura e escrita.

Para melhorar a prática de leitura/escrita, busquei estratégias alternativas de letramento com os alunos, já que não adotava o livro didático. A opção por essas estratégias deveu-se ao fato de proporcionarem aos alunos o contato com os três eixos que norteiam o ensino de Língua materna: leitura, oralidade e escrita, e integrararem de forma dinâmica expressividade, emoção e pensamento

a) Hora da contação de histórias: sentava com os alunos embaixo das árvores do colégio e cada um contava uma história que havia lido ou escutado, ou trazia ao colégio pessoas para essa atividade. Havia, nesse momento, um grande respeito pelo que o outro tinha para falar.

b) Jornal falado: os alunos ouviam as notícias pela manhã no rádio e na $\mathrm{TV}$, e as reproduziam em sala, escrevendo e discutindo sobre os assuntos noticiados.

c) Momentos poéticos: utilizei como fio condutor do projeto de letramento dos alunos o livro de poesias "Fazendo Ecoar", de autoria de Edi Tozetto. As poesias versavam sobre temáticas do cotidiano dos alunos: tabuada, provas, geografia, pai, mãe, futebol, religião. A presença da poetisa na escola durante quatro meses, foi significativa para os alunos. Ela integrou-se ao projeto, coordenando oficinas de produção e declamação de poesias. Ao longo do ano escolar, os alunos passaram a freqüentar com maior assiduidade a biblioteca, em virtude dos livros doados pela poetisa.

d) Contato com material impresso dos mais variados tipos: jornais, livros, revistas, gibis, anúncios, cartazes, bulas de remédio. Esse material foi selecionado pelo fato de fazer parte da vida dos alunos e com o intuito de levá-los a repensar a leitura e a função social dessa prática lingüística.

e) Reestruturação textual: foi uma prática contínua em sala de aula. Os textos foram reestruturados coletivamente ou em duplas. O trabalho individualizado só foi possível no segundo semestre, a partir do acompanhamento de uma estagiária.

\section{APRESENTANDO RESULTADOS (PORAMOSTRAGEM)}

Nas quintas séries, a atividade de produção escrita ocorre basicamente com o texto narrativo, ou seja, com a produção de histórias. Partindo desse princípio, surgiram as primeiras narrativas escritas pelo grupo em questão. 
Para avaliá-las, utiliza-se geralmente a conhecida fórmula do "lead" jornalístico (Quem? Quando? Com quem? Onde? Como? Por quê?). Porém, com esse grupo isso não foi possível, porque os textos produzidos pelos alunos não se adequavam às questões do lead, configurando-se aquém do esperado para a idade em que esses alunos se encontravam.

As primeiras produções escritas foram guardadas, com o intuito de possibilitar ao aluno a comparação com outros textos produzidos posteriormente e serem retomadas para reconstrução. Na perspectiva sistêmica triádica, os alunos são orientados para a regulação e reorientação da aprendizagem (feedback) a partir da avaliação de sua própria produção, com base nos avanços obtidos. Essa perspectiva é triádica porque envolve simultaneamente pensamento - as estruturas textuais aprendidas; sentimento - auto-estima elevada em função da aprendizagem realizada; e $a c ̧ a ̃ o$ - tornar-se sujeito do processo de aprendizagem via reconstrução.

Os textos transcritos abaixo foram produzidos a partir da seqüência das seguintes palavras: o anúncio, o circo, o dinheiro, o espetáculo, palhaços, trapezistas, malabaristas, animais, globo da morte, a volta.

\section{O circo (texto escrito no começo do ano letivo)}

Num manhã um circo a pareceu o anúncio na televisão e mideu uma vontade de $i$ no circo. Eu nào tinha dinheiro para ida ao circo. E espera do início do espetáculo. Os palhaços era chato.

Pode-se observar que esse texto reproduz a estrutura de orações fragmentadas presentes em textos tradicionais encontrados em cartilhas de alfabetização. O léxico reflete a linguagem coloquial do aluno; os signos utilizados reproduzem as situações peculiares de seu grupo social. Das dez palavras sugeridas para dar seqüência ao texto, foram utilizadas apenas cinco, o que comprometeu a compreensão do texto.

Ao final do ano, o aluno produz o seguinte texto, atendendo às mesmas orientações:

\section{O circo (texto reestruturado)}

Numa certa manhã apareceu um anúncio sobre um circo que iria estar em Ponta Grossa. E me deu uma vontade de assistir o espetáculo. Só que havia um pequeno problema: eu não tinha dinheiro.

Fui pedir para minha avó e ela me deu uns trocadinhos.

A ida ao circo foi legal e ao chegar lá eu vi uns doces e salgados saborosos e fiquei morrendo de vontade, só que se eu comprasse doces eu teria que voltar a pezinho para casa. Pensei melhor e desisti das gulas.

O espetáculo começou e meu coração disparou. Primeiro veio os palhaços, depois os trapezistas,

Olhar de professor, Ponta Grossa, 8(1): 171-186, $2005 . \overline{181}$ 
os malabaristas, os animais e por último o globo da morte e foi o que eu mais gostei.

Quando terminou o espetáculo voltei correndo para casa bem feliz e com muita fome.

O processo de autoregulação realizou-se satisfatoriamente, uma vez que o aluno conseguiu atingir os objetivos de produção escrita correspondente à quinta série, estabelecendo a seqüência lógica e o uso do lead, apesar de conter algumas falhas de concordância e pontuação. Ele demonstrou compreender os usos da língua, independentemente de seus mecanismos regidos por convenções.

A leitura de imagens revelou-se eficaz para a melhoria da escrita dos alunos, como se pode constatar nos exemplos abaixo, em que, a partir de uma tira de história em quadrinhos sem legendas, o aluno deveria escrever um texto narrativo.

\section{O susto (primeiro texto)}

O Chico está lendo e uma onça vem e dá um susto nele e ele sai correndo e a onça fica ali lendo a revista dele.

Esse texto foi escrito pelo aluno antes de ser explorada pela professora a questão semiótica das imagens.

O susto (segundo texto)

Certo dia, Chico Bento chegou da escola meio cansado e resolveu prar pra relaxar a cabeça, pois ele tinha brigado com sua namorada, pensou em ler uma revista que tinha encontrado em uma pedra. Pegou a revista e sentou encostadinho na pedra, bem tranqüilo.

De repente saiu uma onça pintada do meio dos arbustos e ela meio curiosa ficou pensando:

- O que terá de interessante naquela revista?

De surpresa a onça avançou em Chico e ele saiu correndo de medo e a onça que era muito esperta tomou o lugar e a revista do Chico, ficando ali na maior tranqüilidade.

No primeiro texto constata-se uma leitura superficial das imagens. No segundo, produzido após a exploração semiótica das imagens, o aluno conseguiu realizar uma leitura mais condizente com as imagens da tira. Constata-se a seqüência e a coerência textual. Os alunos dessa turma produziram muitos textos e a prática de reestruturação individual e coletiva foi constante durante o ano, incidindo sobre os problemas que os textos narrativos apresentavam (lead, seqüência e o que torna um texto viável).

Essa conquista só foi possível na medida em que, concomitantemente, investiu-se na auto-estima dos alunos, mobilizando emoções e sentimentos positivos, estimulando a autonomia e autoregulação do comportamento aprendente. 
A seguir, são transcritos dois textos de caráter opinativo de um mesmo aluno: o primeiro escrito no início do ano letivo e o segundo na fase final do projeto de letramento. Esses textos não foram reestruturados, a fim de possibilitar a visualização do progresso na produção escrita do aluno.

\section{Texto 1 (inicio do ano)}

Izistia uma família feliz e todos fazião auguma coisa como lavar a louça servir o aumoço varer a casa Mais tinha dia que era tudo aus contrario $O$ pai assistindo teve filho brincando de avião apenas mãe e filha mais no outro dia pai estava lavando losa e filho secando e mae fazendo as unhas e a filha brincando mas teve dia que eles agiram serto todos ajudaram e foi certo.

Texto 2 (final do ano)

\section{O Consumismo}

Hoje em dia, as pessoas não se contentam com o que tem, sempre querem mais e sempre o que está na moda.

O consumismo não leva a lugar algum, quer dizer, leva a falência, porque do jeito que as pessoas gastam o dinheiro acaba bem rápido, rápido do jeito que elas compram.

No princípio elas querem com- prar coisas baratas como bolsas, calçados. Assim vai indo até chegar em coisas bem caras como carros, casas. O consumismo pode até ser uma doença, pois as pessoas não conseguem segurar $o$ dinheiro, quando tentam economizar é por pouco tempo, não se controlam e já saem gastando.

Ultimamente, as pessoas são influenciadas a gastar, principalmente pelas lojas e Shopping que fazem muitas liquidações de arrasar.

Eu não me considero consumista, pois eu não gosto de gastar muito, minha mãe não deixa e também eu não tenho muito dinheiro para gastar, só gasto o que é preciso para viver.

(Os dois textos foram produzidos pelo mesmo aluno de $5^{\mathrm{a}}$ série, 13 anos, de uma escola estadual de Ponta Grossa, no ano de 2003).

\section{CONTEXTUALIZANDO AS CON- DIÇÕES DE PRODUÇÃO DO TEXTO 1}

O texto 1 foi escrito nas primeiras semanas de aula; a temática girava em torno da questão familiar. Foi solicitado aos alunos que observassem três cenas de convívio familiar e escrevessem sobre a que lhes parecia a mais justa, justificando o porquê dessa escolha. Sobre as outras, os alunos deveriam manifestar apenas a opinião pessoal:

Olhar de professor, Ponta Grossa, 8(1): 171-186, $2005 . \overline{183}$ 
- $1^{\text {a }}$ cena: a mãe e a filha fazendo sozinhas o trabalho doméstico, o filho brincando e o pai assistindo à TV e tomando cerveja;

- 2 cena: a mãe é quem dá as ordens. Ela está assistindo TV, fazendo as unhas e a filha brincando, enquanto o pai e o filho estão fazendo as tarefas domésticas;

- $3^{\text {a }}$ cena: todos estão ajudando nas tarefas domésticas.

No texto do aluno, percebe-se que ele descreveu as cenas de modo superficial; emitiu seu parecer, porém aquém do esperado de um aluno na faixa etária de 13 anos. Observa-se, ainda, que o texto possui problemas ortográficos, não há parágrafos, nem pontuação. Parece que o aluno escreveu apenas para se ver livre da tarefa proposta e garantir a nota - prática de anos anteriores. Na ficha individual do aluno, constava que ele "odiava escrever".

CONTEXTUALIZANDO AS CONDIÇÕES DE PRODUÇÃO DO TEXTO2

Com relação ao segundo texto do mesmo aluno, cuja temática foi a da leitura de imagens de propagandas anunciadas pela mídia e debates sobre o consumismo, pôde-se observar que houve evolução, pois ele conseguiu escrever com grau maior de coesão, usou parágrafos adequadamente, expressou sua opinião sobre o tema, argumentou e utilizou repertório vocabular bem mais elaborado.

Esses dois textos retratam, no aspecto microssocial, o que ocorreu no aspecto macrosocial da turma, uma vez que ao final do ano todos os alunos estavam lendo com fluência e escrevendo textos narrativos e opinativos de acordo com os parâmetros desejáveis para alunos dessa faixa etária. Houve apenas um aluno que repetiu a série, em virtude de desistência. Os demais foram aprovados para a série seguinte, ultrapassando as expectativas fantasmagóricas da reprovação escolar, que em anos anteriores alcançava $30 \%$ dos alunos da turma de $5^{\text {a }}$ série daquela escola.

\section{CONCLUSÃO}

$\mathrm{O}$ que tem ocorrido em nossas escolas é que o espaço destinado à leitura nas aulas pode ser caracterizado como monótono e padronizado, pois muitos dos livros didáticos adotados apresentam uma concepção distorcida sobre o ensino de leitura, e privilegiam a cópia e a memorização de conteúdos gramaticais. Para o professor, a utilização do livro didático como única fonte para o ensino da língua materna restringe as possibilidades de utilização de outras estratégias de ensino mais condizentes com os avanços da neurociência, considerando-se que o campo da educação é interdisciplinar.

A aprendizagem da leitura e da 
escrita é um processo criativo de construção e produção de conhecimento. Contudo, o que acontece em sala de aula foge a esse princípio: o que se vê é um distanciamento do aluno de seu objeto de conhecimento. O processo de leitura deveria ser holístico, buscando a visão do todo, pois as práticas fragmentadas de leitura através do bê-a-bá acarretam sérios problemas para a formação do leitor. O texto precisa ser entendido no seu sentido global, independente da natureza do signo de que se constitui e do veículo em que se faz circular. Na perspectiva sistêmica triádica, a aprendizagem não pode ser limitada a programas pré-estabelecidos ou a apenas uma das dimensões do cérebro triádico. Há que ser integrativa dos aspectos cognitivos, afetivos e motores. Foram esses os fundamentos filosóficos e epistemológicos de minha atuação docente junto à referida turma de alunos.

Passei a confiar mais no meu trabalho docente a partir da utilização da perspectiva sistêmica triádica, porque consegui recuperar e trazer para o recinto escolar o prazer pelo aprendizado da leitura e escrita. Pude experienciar a sinergia do processo de ensino-aprendizagem e concluir que saberes codificados transmutam-se em conhecimento, quando acompanhados de sentido e de afeto.

\section{REFERENNCIAS}

\author{
ARAUJO, M. C. Didática cotidiana na \\ família, escola e empresa. São Paulo: \\ Lorosae, 2002.
}

BEAUPORT, E.; DIAZ, A. S. Inteligência emocional: as três faces da mente. Brasília: Teosófica, 1998.

BRASIL. Secretaria da Educação Fundamental. Parâmetros curriculares nacionais: terceiro e quarto ciclos do ensino fundamental (Língua Portuguesa). Brasília: MEC/SEF, 1998.

GOLdstein, S.; GOdstein, M. Hiperatividade: como desenvolver a capacidade de atenção da criança. Campinas: Papirus, 1998.

MAIA, D. Método de ensinagem sistêmica. São Paulo: Lorosae, 2002.

MATENCIO, M. L. M. Leitura, produção de textos e a escola: reflexões sobre o processo de letramento. Campinas: Mercado das Letras, 1994.

MAHONEY, M. J. Processos humanos de mudança: as bases científicas da psicoterapia. Porto Alegre: Artmed, 1998.

OLIVEIRA, C. C. Psicologia da ensinagem. Goiânia: ASA, 2003.

Psicologia da ensinagem: psicologia dos processos mentais na relação professor/aluno. Brasília: Kelps, 1998.

OLIVEIRA, G. C. Dificuldades subjacentes ao não - aprender. In: SISTO, F. F.; BORUCHOVITCTH, E.; FINI, L. D. T. Dificuldades de aprendizagem no contexto psicopedagógico. Petrópolis: Vozes, 2001. 
Psicomotricidade: educação e reeducação num enfoque psicopedagógico. Petrópolis: Vozes, 1999.

RONCHIM, S. M. R. Psicopedagogia no ambiente hospitalar: um estudo de crianças com dificuldades de aprendizagem. Dissertação (Mestrado) - Universidade Estadual de Campinas, Campinas, 1999.
ROMÁN, S. W. Disciplina: o que fazer falando de convivência. Philos, Florianópolis, v. 4, n. 8, p. 14-18, 1997.

SANTAELLA, L. O que é semiótica. São Paulo: Brasiliense, 1990.

ZAGURY, T. Encurtando a adolescência. Rio de Janeiro: Record, 1999.

Encaminhado em 19/07/2004

Aceito em 18/04/2005

\section{ANEXO 1 - QUESTIONÁRIO UTILIZADO PARA AVALIAR AS QUESTÕES SÓCIO-ECONÔMICAS QUE PODEM ESTAR DIFICUL- TANDOAAPRENDIZAGEM}

1. Nome completo do aluno e idade.

2. Nome dos pais e idade.

3. Endereço/casa própria ou alugada/distância da escola/utiliza condução para vir para a escola/telefone para contato.

4. Estado civil/profissão dos pais/escolaridade dos pais/salário.

5. Quando tem alguém doente em casa, vão ao posto de saúde mais próximo? Como fazem para dar assistência a alguém que está doente em casa?

6. Quais desses alimentos você sempre tem em sua casa: pão, leite, carne, frutas, verduras, feijão, arroz, macarrão, doces, entre outros?

7. Alguém em sua casa fuma, toma bebidas alcoólicas, toma remédios de uso continuado?

8. O que você faz nas horas vagas? Passeia? Vai aonde?

9. Qual é a religião da sua família?

10. Você assiste TV? Quantas horas por dia?

11. Você gosta de ler? Lê revistas, jornais, livros?

12. De qual escola você veio? Gosta de vir à escola? Por quê?

13. De que disciplina você mais gosta? 